\title{
Processo de Formatação de Atrativos Turísticos Sustentáveis
}

\author{
Formatting Process of Sustainable Tourism Attractions
}

\section{Proceso de Formatación de Atracciones de Turismo Sostenible}

\author{
Cássio dos Santos e Oliveira ${ }^{1}$ \\ Maria Henriqueta Gimenes-Minasse ${ }^{2}$ \\ Sílvio César Moral Marques ${ }^{3}$
}

\begin{abstract}
Resumo
Este artigo parte do pressuposto que o planejamento do destino turístico, com base nas premissas do desenvolvimento sustentável, deve focar e ressaltar seus atrativos turísticos, uma vez que esses elementos são responsáveis por promover o deslocamento de visitantes. Assim, a organização dos atrativos turísticos impacta na competitividade do destino no mercado turístico. Este estudo tem como objetivo o desenvolvimento de um processo de formatação de atrativos turísticos sustentáveis. Os dados que subsidiam as reflexões aqui apresentadas foram coletados a partir de pesquisa bibliográfica e documental. $\mathrm{O}$ resultado final é a apresentação de um processo de formatação de atrativos turísticos, com uma abordagem prática e operacional no formato de auto solução, onde o proprietário e/ou gestor de atrativos turísticos, bem como os técnicos de projetos de turismo do SEBRAE-SP sejam capazes de implementar os procedimentos propostos neste trabalho. Este processo de formatação é composto por três etapas de desenvolvimento de atrativos turísticos (interpretação, diagnóstico e intervenção) que está alicerçado em cinco eixos estratégicos de análise (características do produto; estrutura física; segurança; gestão; promoção e comercialização). Espera-se que, ao contribuir para a análise da formatação de atrativos turísticos sustentáveis, possa-se criar subsídios para o processo de planejamento de destinos turísticos, no sentido de incrementar a qualidade das atividades de lazer e as experiências oferecidas, bem como orientar os profissionais que atuam diretamente na gestão desses equipamentos turísticos.
\end{abstract}

Palavras-chave: Atrativo turístico; Planejamento; Formatação; Sustentabilidade; SEBRAESP.

\footnotetext{
${ }^{1}$ Mestre em Sustentabilidade na Gestão Ambiental pela Universidade Federal de São Carlos, gestor da área de Turismo SEBRAE São Paulo. Brasil. E-mail: cassioos@sp.sebrae.com.br

${ }^{2}$ Professora e pesquisadora na Universidade Anhembi Morumbi Doutora em História pela Universidade Federal do Paraná. Brasil. E-mail: mariegimenes@gmail.com

${ }^{3}$ Professor e pesquisador na Universidade Federal de São Carlos Doutor em Filosofia pela Universidade de São Paulo. Brasil. E-mail: silviocmm@ufscar.br
} 


\begin{abstract}
This article assumes that the planning of tourist destination, based on the assumptions of sustainable development should focus on and highlight its tourist attractions, since these elements are responsible for promoting the movement of visitors. The organization of tourist attractions impacts the fate of competitiveness in the tourism market. This study aims to develop a process of formatting sustainable tourist attractions. The data that support the ideas presented here were collected from bibliographical and documentary research. The end result is the presentation of a process of formatting tourist attractions, with a practical and operational approach to self solution format, where the owner and / or manager tourist attractions as well as the technical tourism projects SEBRAE-SP are capable of implementing the procedures proposed in this work. This formatting process consists of three stages of development of tourist attractions (interpretation, diagnosis and intervention) that is built on five strategic axes of analysis (product characteristics, physical structure, security, management, promotion and marketing). It is expected that, by contributing to the analysis of formatting sustainable tourist attractions, can be created subsidies for the planning process of tourism destinations, in order to increase the quality of leisure activities and experiences offered, as well as guide professionals who work directly in the management of these tourist facilities.
\end{abstract}

Keywords: Tourist attraction; Planning; Formatting; Sustainability; SEBRAE-SP.

\title{
Resumen
}

Este artículo se supone que la planificación del destino turístico, con base en los supuestos de desarrollo sostenible debe centrarse y resaltar sus atractivos turísticos, ya que estes son responsables de promover la circulación de los visitantes. La organización de las atracciones turísticas impactos el destino de la competitividad en el mercado turístico. Este estudio tiene como objetivo desarrollar un proceso de formatear y atracciones turísticas sostenibles. Los datos que apoyan las ideas que aquí se presentan se obtuvieron de la investigación bibliográfica y documental. El resultado final es la presentación de un proceso de formatear y lugares de interés turístico, con un enfoque práctico y operativo al formato de sistema de autogestión, donde el dueño y / o gerente de atracciones turísticas, así como el técnico de turismo de proyectos del SEBRAE-SP son capaces de implementar los procedimientos propuestos en este trabajo. Este proceso de formato consiste en tres etapas de desarrollo de las atracciones turísticas (interpretación, diagnóstico e intervención) que se basa en cinco ejes estratégicos de análisis (las características del producto, estructura física, seguridad, gestión, promoción y comercialización). Se espera que, al contribuir al análisis de formatear atracciones turísticas sostenibles, se pueden crear subsidios para el proceso de planificación de los destinos turísticos, con el fin de aumentar la calidad de las actividades de ocio y experiencias que ofrece, así como la guía profesionales que trabajan directamente en la gestión de estas instalaciones turísticas.

Palabras clave: Atracción turística; Planificación; Formatación; Sostenibilidad; SEBRAESP. 


\section{Introdução}

O turismo pode ser descrito como uma atividade multifacetada que se inter-relaciona com diversos segmentos econômicos e demanda um complexo conjunto de ações setoriais para o seu desenvolvimento (BADARÓ, 2008). Ao longo das últimas décadas, esta atividade vem apresentando um crescimento contínuo e atualmente pode ser considerada como um dos setores mais relevantes na economia mundial. De acordo com as informações da Organização Mundial do Turismo - OMT (2014), de 2000 a 2012, os deslocamentos internacionais de turistas passaram de 689 milhões a 1,03 bilhão no período, representando uma taxa aproximada de 9\% de crescimento ao ano. Em 2012 o Brasil recebeu 5.676 .843 turistas estrangeiros, e só o estado de São Paulo recebeu 2.110.427 turistas internacionais (Anuário Estatístico de Turismo, 2013).

Conforme a publicação do documento "Conta satélite do Turismo: Recomendações sobre o marco conceitual", publicado pelas Nações Unidas em 2008, o setor de turismo pode ser entendido como:

(...)um fenômeno impulsionado pela demanda, [que] se refere às atividades de visitantes e ao seu papel na aquisição de bens e serviços. Também pode ser considerado do ponto de vista da oferta, caso em que o turismo significa um conjunto de atividades produtivas projetado para atender principalmente os visitantes. O turismo é um fenômeno social, cultural e econômico que desenvolve o movimento de pessoas. (NAÇÕES UNIDAS, 2008, p. 1).

Assim, como afirma Coriolano (2006), o turismo é uma prática social, que reúne oportunidades de aquisição cultural, troca de experiências, realização de sonhos, busca de emoções e formas de aprendizagem. Para que estas possibilidades se concretizem, contudo, ações de planejamento são necessárias. O planejamento é, segundo Molina e Rodriguez (2001), o resultado de um processo lógico de pensamento, mediante o qual analisa-se a realidade abrangente e se estabelece os meios que vão permitir transformá-la de acordo com as necessidades, interesses e aspirações. De forma específica, o planejamento turístico pode ser considerado como:

(...) o processo de avaliação do núcleo receptor (comunidade, oferta turística e demanda real) da demanda potencial e de destinos turísticos concorrentes, com o intuito de ordenar as ações de gestão pública direcionadas ao 
desenvolvimento sustentável e, consequentemente, fornecer direcionamento à gestão privada para que ela estruture empreendimentos turísticos lucrativos com base na responsabilidade socioambiental. (BRAGA, 2007, p. 7).

De acordo com o autor é necessário organizar as informações de forma a orientá-las em ações que promovam um planejamento turístico. E, para tanto, faz necessário estabelecer as etapas do planejamento turístico. Para Petrocchi (2001), as etapas de um planejamento turísticos são:

- diagnóstico: é a etapa em que se analisa a situação existente. A qualidade do processo como um todo, nasce nesta fase. Um bom diagnóstico é imprescindível para a qualidade de todo o processo;

- determinação de objetivos: é a determinação da situação planejada para o futuro. É uma meta a ser atingida. Os objetivos são o ponto de convergência de toda a organização;

- estratégias e meio: após análise da situação presente e determinados os objetivos, a etapa seguinte é a escolha das estratégias e a definição dos meios necessários;

- planos de trabalho: são as ações necessárias para que os objetivos sejam alcançados. Situam-se nos planejamentos tático e operacional e observam as estratégias e os meios escolhidos;

- controle: fase de acompanhamento do processo e de tomar, quando necessário, atitudes corretivas. (PETROCCHI 2001, p. 72).

Como citado pelo autor, para se realizar o planejamento turístico de uma determinada localidade, deve-se realizar um encadeamento lógico dessas etapas de forma que o planejamento seja compatível com a realidade local, tenha objetivos claros e meios para que as ações sejam realizadas.

As ações de planejamento e gestão do turismo no Brasil, no âmbito federal, são responsabilidade do Ministério do Turismo. Atuam também órgãos governamentais estaduais (secretarias e órgãos correlatos), órgãos governamentais municipais (secretarias e departamentos) e de outras instituições, tais como o SEBRAE - Serviço Brasileiro de Apoio às Micro e Pequenas Empresas. Trata-se de um serviço social autônomo, fundado em 1972, como parte integrante do Sistema $\mathrm{S}$ que objetiva auxiliar o desenvolvimento de micro e pequenas empresas estimulando o empreendedorismo no país. Hoje o SEBRAE conta com sua sede nacional em Brasília e está presente nas 27 unidades da Federação através de unidades estaduais, dentre elas a do Estado de São Paulo. 
A atuação no setor de turismo do SEBRAE-SP surgiu a partir da criação do núcleo de turismo, em 1998, que tinha por objetivo consolidar a atividade turística de forma municipal. O primeiro programa de Turismo, denominado PST - Programa Sebrae de Turismo, disponibilizava aos municípios paulistas interessados em desenvolver o turismo um contrato de prestação de consultoria que contemplava 240 horas. Dentre as atividades realizadas nesta consultoria estavam a orientação para a implementação de Conselhos Municipais de Turismo - COMTURs, conforme estabelecido pelo então vigente Plano Nacional de Municipalização Turística - PNMT (SEBRAE SP, 2011).

Atualmente o SEBRAE-SP está presente em todo o estado através de 33 escritórios regionais. Estes escritórios regionais respondem pelo atendimento aos micro e pequenos empresários dos setores de agronegócios, indústria, comércio e serviços. As principais ferramentas disponíveis para estes empresários são cursos, oficinas, palestras, projetos, programas e consultorias - individuais e coletivas. Atualmente, o SEBRAE-SP atua no desenvolvimento de 12 projetos de circuito/roteiro turístico, envolvendo cerca de 30 funcionários no atendimento a esses projetos, totalizando um atendimento a 3.800 micro e pequenas empresas do setor de turismo.

O documento base desta atuação é o "Método para construção, estruturação e implementação de projetos em circuitos e roteiros turísticos", que tem por objetivo ser um referencial prático do SEBRAE-SP para a elaboração e execução de projetos no setor de turismo. Criado em 2011, este método orienta os gestores técnicos dos escritórios regionais do SEBRAE-SP na elaboração de projetos de turismo, bem como descreve as responsabilidades de todos os envolvidos no processo de desenvolvimento de um destino turístico.

Este método, apesar de apresentar informações detalhadas para o desenvolvimento de um destino turístico, não apresenta um capítulo ou seção com informações particularizadas sobre a formatação de atrativos turísticos sustentáveis, o que revela uma lacuna no processo de fortalecimento e consolidação da oferta do destino turístico. De maneira sintética, o manual enfatiza a importância dos atrativos na motivação e criação de fluxos turísticos, mas não esclarece como isso pode ser feito, na medida em que não aborda principais pontos a serem trabalhados na formatação desses atrativos turísticos. Esta lacuna, considerando o processo de planejamento turístico como um todo, é uma pendência importante, inclusive para aqueles que 
são responsáveis pela aplicação do método in loco, na destinação turística. E, justamente por considerar a importância da atuação do SEBRAE-SP no desenvolvimento de projetos de Circuitos e Roteiros Turísticos realizou-se uma pesquisa que deu origem a uma dissertação de mestrado desenvolvida junto ao Mestrado em Sustentabilidade na Gestão Ambiental (UFSCAR) que visa contribuir para a complementação deste material nesta questão.

Este artigo tem, portanto, como objetivo geral apresentar uma complementação do "Método para construção, estruturação e implementação de projetos em circuitos e roteiros turísticos" SEBRAE-SP no que se refere ao processo de formatação de atrativos turísticos sustentáveis.

\section{Método}

As proposições aqui apresentadas foram concebidas a partir de uma revisão bibliográfica (destinada a identificar e refletir sobre os conceitos fundamentais relacionados à formatação de atrativos turísticos sustentáveis) e de uma pesquisa documental (que buscou conhecer melhor outras iniciativas que poderiam contribuir no resultado proposto). Os principais documentos analisados neste estudo foram a Metodologia de hierarquização de atrativos turísticos do "Programa de Regionalização do Turismo" (2007), o "Inventário da Oferta Turística" (2011) e o "Termo de Referência para atuação em Turismo Receptivo do SEBRAE-SP" (2011), além do próprio "Método para construção, estruturação e implementação de projetos em circuitos e roteiros turísticos" do SEBRAE-SP (2011). Seguem, de maneira sintética, as principais características e contribuições destes documentos para este trabalho.

A metodologia de hierarquização de atrativos turísticos do Programa de Regionalização do Turismo foi desenvolvida pelo Ministério do Turismo, que através deste programa tem por objetivo apoiar a gestão, estruturação e promoção do turismo no Brasil, de forma regionalizada e descentralizada. Dentre diversos módulos operacionais apresentados por este programa, destaca-se o módulo operacional 7 - Roteirização turística, que aborda a maneira de organizar e integrar a oferta turística brasileira, e descreve os produtos, serviços e equipamentos turísticos, além das atividades complementares relacionadas ao turismo. Neste módulo o MTur propõe uma adaptação na metodologia utilizada pela OMT e pelo CICATUR 
para a hierarquização de atrativos turísticos, de seis para quatro níveis de hierarquização, sendo eles:

- hierarquia 3 (alto) - É todo atrativo turístico excepcional e de grande interesse, com significação para o mercado turístico internacional, capaz de, por si só, motivar importantes correntes de visitantes, atuais e potenciais.

- hierarquia 2 (médio) - Atrativos com aspectos excepcionais em um país, capazes de motivar uma corrente atual ou potencial de visitantes deste país ou estrangeiros, em conjunto com outros atrativos próximos a este.

- hierarquia 1 (baixo) - Atrativos com algum aspecto expressivo, capazes de interessar visitantes oriundos de lugares no próprio país, que tenham chegado à área por outras motivações turísticas, ou capazes de motivar fluxos turísticos regionais e locais (atuais e potenciais).

- hierarquia 0 (nenhum) - Atrativos sem méritos suficientes, mas que são parte do patrimônio turístico como elementos que podem complementar outros de maior hierarquia. Podem motivar correntes turísticas locais, em particular a demanda de recreação popular. (BRASIL, 2007, p.46).

O mesmo documento apresenta aspectos que permitem classificar cada atrativo turístico de acordo com uma escala preestabelecida, fornecendo subsídios para a diferenciação objetiva das características e dos graus de importância de cada produto turístico atrativo. Essa análise pode ser feita por profissionais do setor de turismo, bem como por empresários interessados em avaliar o grau de atratividade do seu empreendimento. Os aspectos de classificação apontados pelo MTur são:

- Grau de uso: Permite analisar o atual volume de fluxo turístico efetivo e sua importância para a localidade. Difere do grau de interesse por representar a situação atual, ao invés do potencial. Um alto grau de uso indica que o atrativo apresenta uma utilização turística efetiva;

- Representatividade: Fundamenta-se na singularidade ou na raridade do atrativo. Quanto mais se assemelhar a outros atrativos, menos interessante ou prioritário;

- Apoio Local: A partir da opinião dos líderes comunitários, deve-se analisar o grau de interesse da comunidade local para o desenvolvimento e disponibilidade ao público;

- Estado de conservação da paisagem circundante: Verificar por observação in loco, o estado de conservação da paisagem que circunda o atrativo. Neste item é analisado a ambiência do atrativo;

- Infraestrutura: Verificar, in loco, se existe infraestrutura disponível no atrativo e o seu estado;

- Acesso: Verificar as vias de acesso existentes e suas condições de uso (BRASIL, 2007, p. 47). 
Estes aspectos auxiliam a avaliação realizada no atrativo turístico uma vez que estabelecem parâmetros claros a serem considerados na hierarquização de atrativos turísticos.

Esta metodologia contribuiu efetivamente para o entendimento sobre o potencial de atratividade de cada atrativo turístico, auxiliando na definição dos eixos estratégicos e consequentemente nas etapas do processo de formatação de atrativos turísticos sustentáveis.

Outro documento analisado neste trabalho, foi a metodologia do Inventário da Oferta Turística do MTur. Esta metodologia tem por objetivo de levantar, identificar, registrar e divulgar os atrativos, serviços e equipamentos turísticos, as estruturas de apoio ao turismo, as instâncias de gestão e outros itens e condições gerais que viabilizam a atividade turística. Essas informações são obtidas a partir do inventário da oferta turística e servem para fundamentar o planejamento e a gestão do turismo. A metodologia está organizada em três categorias sendo elas i) Categoria A - Infraestrutura de apoio ao turismo; ii) Categoria B Serviços e equipamentos turísticos; e iii) Categoria $\mathrm{C}$ - Atrativos turísticos.

A categoria $\mathrm{C}$ é específica para o levantamento de informações sobre os atrativos turísticos e está subdividida em 5 subcategorias: atrativos naturais; atrativos culturais; atividades econômicas; realizações técnicas e científicas contemporâneas; e eventos programados.

Considera-se este processo de inventariação turística bastante completo, por apresentar os formulários de pesquisa da oferta turística, bem como um sistema - INVTUR ${ }^{4}$, para integrar e compartilhar todas as informações referentes a oferta turística dos municípios brasileiros. Porém ao se analisar esta metodologia, percebe-se que não há um processo de continuidade no que se refere à estruturação da oferta turística. Entende-se que o processo de inventariação é uma etapa de diagnóstico, onde deve ser primordial estabelecer os processos de continuidade a fim de se aprimorar e aperfeiçoar a oferta turística de um determinado destino.

Esta metodologia contribuiu para a formulação das etapas do processo de formatação de atrativos sustentáveis, mais especificamente na etapa de diagnóstico que tem por objetivo nortear e facilitar este processo.

Outro documento analisado foi o Termo de Referência para atuação em turismo Receptivo do SEBRAE-SP, que entende como atrativo turístico o recurso natural (propriedade rural, cachoeira, rio, lago, etc.) ou cultural (casarão, grupo folclórico, de dança ou musical, dentre

\footnotetext{
${ }^{4}$ Sistema de Inventariação da Oferta Turística - INVTUR, é um ambiente virtual que permite resgatar, reunir, organizar e fazer circular dados e informações atualizadas sobre o inventário do turismo brasileiro.
} 
outros) formatado em negócio, atendendo a todas as especificações necessárias para comercialização e recepção de turistas, com responsabilidade social, ambiental e cultural. Enquanto negócio, o atrativo turístico precisa ser gerido como qualquer empresa, ter estrutura mínima para receber clientes, oferecendo experiências de forma organizada e profissional, a fim de produzir resultados positivos.

Do ponto de vista empresarial, os atrativos turísticos podem ser considerados únicos e cada um deles possui valor e capacidade de atração específica. Portanto, possuem diferentes características, potencial e estrutura para a recepção de turistas, o que caracteriza a necessidade de estruturação dos atrativos turísticos para receber com qualidade os turistas.

Assim, as características dos atrativos turísticos, a qualidade das atividades e experiências oferecidas, a gestão, promoção e comercialização desses empreendimentos são determinantes para o desenvolvimento e nível de competitividade do destino. Dessa forma, é imperativo que a formatação e desenvolvimento sustentável dos atrativos turísticos estejam previstos no planejamento estratégico do destino turístico, para que sejam aproveitados como elementos diferenciadores daquela localidade.

O entendimento do SEBRAE-SP sobre atrativos turísticos, enquanto recurso formatado em negócio que é comercializado e responsável pela recepção de turistas, se assemelha com o conceito adotado por autores aonde definem o atrativo turístico como um elemento que efetivamente recebe visitantes e tem uma estrutura para proporcionar experiências turísticas. O último documento consiste, justamente, no objeto da complementação. O "Método para construção, estruturação e implementação de projetos em circuitos e roteiros turísticos" é apresentado no formato de apostila impressa e está organizado em 3 capítulos, além do item de apresentação do material. O primeiro capítulo trata sobre os indicadores de competitividade, o segundo capítulo trata sobre o nível 1 e terceiro capítulo aborda o nível 2. O quadro 1 sintetiza o conteúdo apresentado no método: 
Quadro 1 - Sumário do método de construção, estruturação e implementação de projetos em circuitos e roteiros turísticos

\begin{tabular}{|c|l|}
\hline CAPÍTULO & \multicolumn{1}{|c|}{ ASSUNTO } \\
\hline \multirow{2}{*}{ Indicadores de Competitividade } & $\begin{array}{l}\text { Indicadores de desempenho elaborados a partir dos focos } \\
\text { estratégicos estabelecidos na metodologia de serviços } \\
\text { customizada para o turismo receptivo. }\end{array}$ \\
\hline Nível 1 & $\begin{array}{l}\text { Matriz de indicadores de competitividade referentes ao nível } \\
1, \text { cronograma de execução das fases e etapas referentes ao } \\
\text { nível 1 e passo a passo das fases do nível 1. }\end{array}$ \\
\hline Nível 2 & $\begin{array}{l}\text { Matriz de indicadores de competitividade referentes ao nível } \\
\text { 2, cronograma de execução das fases e etapas referentes ao } \\
\text { nível 2 e passo a passo das fases do nível 2. }\end{array}$ \\
\hline
\end{tabular}

Fonte: Elaborado pelos autores, baseando-se em SEBRAE-SP (2011)

Elaborado para ser um material de consulta dos técnicos gestores de projetos de turismo e servir como material de uso diário na elaboração e execução destes projetos, este método possui 09 fases divididas em dois níveis (nível 1 e nível 2) que levam ao alcance de indicadores de competitividade específicos. Constam o passo a passo de cada fase e os cronogramas para conclusão de suas respectivas etapas e as atividades de cada etapa e um cronograma parcial para a conclusão de cada fase.

Figura 1 - Método para construção, estruturação e implementação de projetos em circuitos e roteiro turísticos

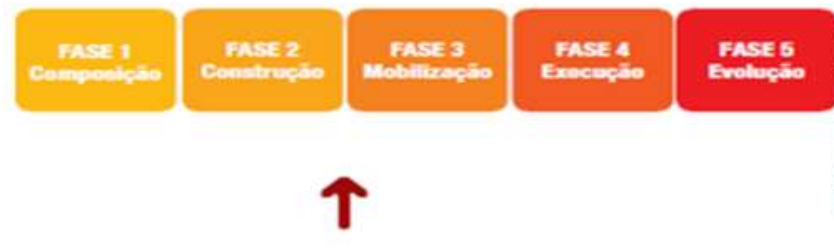

Nivel 1

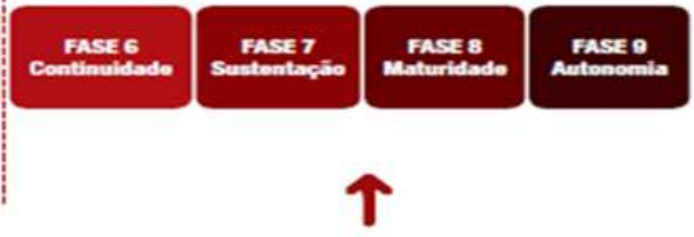

Nivel 2

Fonte: Sebrae-SP (2011)

De forma sucinta, tem-se:

A fase 1 - Composição: compreende a configuração de um território para a implementação de projetos turísticos, onde deverá ser identificada a existência de potencialidade turística (presença de recursos turísticos naturais/culturais), a identificação de possíveis parceiros, um 
grupo de governança ${ }^{5}$ do projeto, bem como ações para fortalecimento, consolidação e manutenção desta governança.

A fase 2 - Construção: compreende o dimensionamento dos segmentos de público alvo que serão trabalhados no projeto, mensuração inicial dos indicadores de competitividade de nível 1 e as oficinas para nivelamento técnico conceitual, planejamento estratégico e estruturação do projeto.

A fase 3 - Mobilização: caracteriza-se pela formatação do projeto com as especificações das ações (com a nominação dos responsáveis pelas mesmas), validação da proposta de projeto junto com a coordenação estadual do SEBRAE-SP e posteriormente com a governança local, realização de um acordo de resultados com os objetivos e resultados propostos no projeto e a formalização de adesão do público alvo que será atendido no projeto.

A fase 4 - Execução: abrange a gestão continua do projeto, a integração dos segmentos de público alvo e a implementação do projeto conforme estabelecidas e validadas as ações nas fases 2 e 3 .

A fase 5 - Evolução: configura a última fase do nível 1 deste método e prevê a realização da mensuração final dos indicadores de competitividade de nível 1 (com a avaliação final de evolução), reunião de avaliação para decisão de continuidade do projeto e evento de encerramento do projeto.

Com a conclusão da fase 5 entende-se que a localidade que teve seu projeto implementado, vive uma nova realidade a partir dos resultados obtido nas fases anteriores. E por estar com esta nova realidade, faz-se necessário estabelecer novas estratégias, ações e resultados. E para isto devem ser implementadas as etapas de nível 2, que tem início na fase 6 - Continuidade que estabelece a realização de redimensionamento dos segmentos de público alvo, novas ações para fortalecimento, consolidação e manutenção da governança local, a mensuração inicial dos indicadores de competitividade de nível 2, a realização das oficinas de aprimoramento técnico conceitual, planejamento estratégico de nível 2 e reestruturação do projeto.

\footnotetext{
${ }^{5}$ Processo contínuo, dinâmico e complexo de tomada de decisão, levando-se em conta a repartição de poder entre governantes e governados, onde indivíduos e instituições (públicas e privadas) gerenciam seus problemas comuns, acomodando interesses conflitantes ou diferenciados e realizando ações de forma cooperada. Visa garantir o comprometimento dos agentes locais na sustentabilidade do processo. A governança pode ser ou conter uma rede de parceiros. (SEBRAE, 2011).
} 
A fase 7 - Sustentação: compreende a formatação do projeto com as especificações das novas ações (com a nominação dos responsáveis), validação desta nova proposta com a governança local, elaboração de um novo acordo de resultados e a adesão do público alvo a ser atendido no projeto.

A fase 8 - Maturidade: envolve a gestão contínua do projeto, a integração dos segmentos de público alvo e a implementação do projeto, conforme as ações estipuladas nas fases anteriores do nível 2.

A fase 9 - Autonomia: é a última fase do método e abarca a realização da mensuração dos indicadores de competitividade de nível 2 (com a avaliação final da evolução do projeto), e evento de encerramento do projeto para apresentar a todos os interessados os resultados obtidos na implementação do projeto de circuito/roteiro turístico.

Para a conclusão de todas as fases do nível 1 são necessários 13 meses úteis e, para concluir o nível 2, mais 11 meses úteis. Isso significa que para a conclusão do método e alcance dos indicadores de competitividade específicos são necessários 24 meses úteis. Levando em consideração que cada ano possui 4 meses não uteis ${ }^{6}$ para o projeto, ou melhor, 4 meses de alta temporada (geralmente julho/dezembro/janeiro/fevereiro), para a conclusão do método são necessários 03 anos corridos. O método traz ainda as orientações de todas as oficinas participativas e procedimentos previstos no método e ainda os seminários que são aplicados junto ao público-alvo na fase de implementação dos projetos.

\section{Resultados}

\subsection{Revisão bibliográfica}

Antes que o método seja apresentado, é importante refletir sobre alguns conceitos fundamentais neste processo: mercado turístico, oferta turística, atrativo turístico e produto turístico. Para Lohmann e Panosso Netto (2012) o mercado turístico se baseia no confronto entre a demanda (os consumidores), os produtores ou vendedores de produtos e serviços turísticos (as empresas hoteleiras, as agências de viagem, as empresas organizadoras de

\footnotetext{
${ }^{6}$ Meses não úteis são considerados os meses de alta temporada, onde geralmente o micro e pequeno empresário não tem a disponibilidade de horário para realizar capacitações, pois necessita ter um foco de atenção maior devido ao aumento de clientes nessas épocas do ano.
} 
eventos, as empresas que atuam na área de entretenimento, de transporte, gastronomia, dentre outras).

Pode-se entender a demanda turística como um conjunto de bens e serviços que os turistas necessitam e são capazes de consumir. Para Lohmann e Panosso Netto (2012) a demanda turística é o total de pessoas (turistas) participando em atividades turísticas, quantificado como o número de chegadas ou saídas de turistas, valor em dinheiro gasto ou outros dados estatísticos. Estes turistas apresentam atualmente um novo perfil de consumo que gera novas demandas de bens e serviços, compelindo o mercado turístico a gerar novas adaptações. Para Cooper et al (2001), novo turista não está mais satisfeito com a experiência passiva, mas busca autenticidade nas destinações, valorizando aspectos como o entendimento da cultura, da história e do ambiente e do modo de vida dos povos.

Como resultado, os destinos turísticos devem apresentar uma oferta turística diversificada de modo a atender esta demanda turística a partir desse novo perfil de turistas. Lohmann e Panosso Netto (2012, p. 375) definem a oferta turística como "todos os bens e serviços que estão à disposição dos consumidores-turistas, por um dado preço, em um determinado período de tempo”. Para Beni (2008) a oferta turística é composta por inúmeros elementos tangíveis e intangíveis e não de um só produto bem determinado.

Ainda segundo Beni (2008), é possível identificar dois grupos distintos que somados compõem a oferta turística de uma determinada região. O primeiro grupo, objeto de estudo deste trabalho, denominado oferta turística original e diferencial é composto pelos atrativos turísticos - formatados enquanto negócios - a partir de recursos naturais e/ou culturais. $\mathrm{O}$ segundo grupo, denominado oferta turística técnica, é composto pelos serviços de transporte, agenciamento turístico, meios de hospedagem, alimentação fora do lar e serviços complementares.

A oferta turística de qualquer localidade depende, portanto, da combinação da oferta turística original e diferencial e da oferta turística técnica. Dessa forma, a oferta turística diferencial assume papel importante uma vez que possui a capacidade de atrair os turistas. Para Beni (2008), o consumo da oferta turística é realizado por meio de roteiros interativos espontâneos ou dirigidos, compreendendo a compra de bens e serviços da oferta turística original e diferencial das atrações e dos equipamentos a ela agregados em mercados globais com 
produtos de qualidade e competitivos. Assim, os elementos que compõem a oferta turística original e diferencial são os elementos que irão conferir característica essencial, uma imagem de marca bem distinta ao conjunto dos subprodutos e do produto turístico total. Com a diversificação e sofisticação das preferências dos consumidores por produtos turísticos, a oferta tornou-se mais específica e os gestores se organizaram para atender os diversos nichos de mercado, tais como: turismo cultural, rural, de aventura, náutico, de bem estar, gastronômico, de compras, etc. (Beni, 2008).

Retomando de forma específica a questão do atrativo turístico, observa-se que existem diversas conceituações e denominações sobre o termo. Lohmann e Panosso Netto defendem que nem sempre é possível ter uma única definição sobre atrativo turístico, e em virtude disto identificam-se categorias principais de atrações como naturais ou construídas; nodal ou linear; atrações permanentes ou temporárias; categorias cognitivas; pagas públicas, privadas ou voluntárias e gratuitas ou pagas.

Para Braga (2007), atrativo turístico é um elemento que efetivamente recebe visitantes e tem estrutura para propiciar uma experiência turística. Já Ignarra (2003) afirma que os atrativos estão relacionados com as motivações de viagens dos turistas e a avaliação que os mesmos fazem desses elementos. Uma vez que os atrativos turísticos são responsáveis pelas motivações de viagens e por efetivamente receber estes turistas, é necessário entender como ordenar esses atrativos turísticos a partir da sua responsabilidade no fluxo turístico de uma determinada região.

Para o SEBRAE (2011) um atrativo turístico é o recurso natural ou cultural formatado em negócio que atenda a todas as especificações necessárias para comercialização e recepção de turistas, com responsabilidade social, ambiental e cultural. A identidade e vocação turística de uma determinada região deve ser determinada a partir da existência de recursos e atrativos turísticos que permitam desenvolver determinados segmentos turísticos.

O Centro Interamericano de Capacitação Turística (CICATUR) da Organização dos Estados Americanos (OEA) desenvolveu uma metodologia para hierarquização de atrativos turísticos. Cárdenas Tabares (1994) propõe uma ligeira modificação neste modelo desenvolvido, com a finalidade de ajustar a evolução dos fatores decisivos, importantes e desejáveis para a 
evolução dos atrativos de projetos turísticos. Cárdenas Tabares (1994) classifica os atrativos turísticos como:

- hierarquia 5: atrativo excepcional e de grande significado para o mercado turístico internacional, capaz por si só de motivar uma importante corrente (atual ou potencial) de visitantes, quantificada como uma porcentagem do total da demanda do país ou de algum mercado específico;

- hierarquia 4: atrativo com características excepcionais em um país, capaz de motivar uma corrente (atual ou potencial) de visitantes do mercado interno ou externo, mas em menor porcentagem que os da hierarquia 5, seja por si só ou em conjunto com outros atrativos contíguos;

- hierarquia 3: atrativo com alguma característica chamativa, capaz de interessar a visitantes provenientes de longa distância, seja do mercado interno ou externo, que tivessem chegado a essa zona por outras motivações turísticas, ou capaz de motivar correntes turísticas (atuais ou potenciais) locais;

- hierarquia 2: atrativos com méritos suficientes para serem considerados importantes para o mercado interno, mas sem condições para o turismo receptivo, e que formam parte do patrimônio turístico;

- hierarquia 1: atrativos sem méritos suficientes para serem considerados nas hierarquias anteriores, mas que igualmente formam parte do patrimônio turístico como elementos que podem ser agregados a outros de maior hierarquia no desenvolvimento e funcionamento de qualquer uma das unidades que integram o espaço turístico;

- hierarquia 0: atrativos cujas qualidades não permitem serem incorporados à hierarquia 1, que é o nível mínimo de hierarquização. (CÁRDENAS TABARES, 1994, p. 47).

A hierarquização de atrativos turísticos apresentada por Cárdenas Tabares (1994) possui uma aplicação relativamente complexa. Apesar de apresentar uma escala com graduações pequenas, a hierarquização exige um entendimento técnico e pode apresentar uma subjetividade de acordo com a visão do profissional que aplica essa hierarquização. Porém, já reforça a importância de se classificar os atrativos turísticos, de forma a se obter uma leitura da realidade e buscar estratégias para melhor estruturar a oferta turística diferencial.

A partir do entendimento sobre a importância dos atrativos turísticos (oferta turística diferencial) bem como dos serviços agregados (oferta turística técnica), e a interrelação entre ambos, é possível se discutir o produto turístico de uma determinada localidade. Segundo Lohmann e Panosso Netto (2012) o produto turístico é a soma dos atrativos (naturais, artificiais e humanos), facilidades (alojamento, alimentos e bebidas, entretenimento e diversão, agências de viagens, locadoras de veículos, capacitação, etc) e acessibilidade (marítimo, terrestre e aéreo). 
Retomando a questão do planejamento, pode-se afirmar que, o sucesso da atividade turística, assim como o de outras atividades econômicas, está atrelado ao planejamento realizado de forma integrada e participativa, oferecendo meios adequados à sua implantação. O modelo de desenvolvimento do turismo alicerçado na sustentabilidade - que também pode ser chamado de turismo sustentável - é apontado como uma possibilidade de se promover a inclusão social, a preservação dos recursos naturais, bem como o desenvolvimento socioeconômico. Em uma das primeiras definições para o turismo sustentável, elaborada pela World Commission on Environment and Development - WCED (1987, citado por Ruschmann, 1997), entende-se por desenvolvimento sustentável do turismo aquele que atende às necessidades dos turistas atuais, sem comprometer a possibilidade do usufruto dos recursos pelas gerações futuras. De forma específica, segundo a Organização Mundial do Turismo, o turismo sustentável satisfaz as necessidades dos turistas e as necessidades socioeconômicas das regiões receptoras, enquanto a integridade cultural, a integridade dos ambientes naturais e a diversidade biológica são mantidas para as futuras gerações. (WTO, 1999).

A Organização Mundial do Turismo (1993), utilizando referências da Conferência Globo 90, denominada "Tourism Stream and Action Committee", que ocorreu em Vancouver, Canadá, estabeleceu os seguintes princípios do turismo sustentável:

- O planejamento, o desenvolvimento e a gestão do turismo devem fazer parte da estratégia de conservação e desenvolvimento sustentável para a região, incidindo sobre todos os setores e contando com a participação do setor público, setor privado e grupos sociais;

- Os organismos, entidades e grupos sociais devem respeitar a cultura e o meio ambiente da zona receptora, sua cultura e estilo de vida, sua comunidade tradicional, bem como seus líderes e sua configuração política; - O turismo deve ser planejado e gerido de forma sustentável, considerandose a proteção e uso econômico adequado do meio ambiente natural e social das áreas escolhidas;

- A atividade deve ser guiada pela ideia de equidade, com o objetivo de distribuir justamente os benefícios e os custos entre promotores turísticos, povos e áreas receptoras;

- As informações, estudos e opiniões diversas devem ser considerados e avaliados frequentemente, bem como os efeitos do meio humano e cultural, principalmente no que diz respeito à população local;

- A população local deve ser estimulada a atuar no planejamento e no desenvolvimento do turismo, com assistência do governo, das empresas e dos investidores;

- O controle deverá ser contemplado no desenvolvimento turístico, para que a população possa se beneficiar com as oportunidades e reagir às mudanças. (OMT, 1993, p.33). 
Conforme citado pela Organização Mundial do Turismo (1993), para o turismo sustentável é necessário contemplar o planejamento, o desenvolvimento e a gestão como estratégias do desenvolvimento sustentável. Deve-se respeitar a cultura e o ambiente da localidade receptora, bem como a proteção e uso adequado do ambiente natural e social. Um dos princípios mais relevantes citados, para a dimensão social, refere-se à ideia de equidade onde todos os participantes receberiam os benefícios e os custos justamente distribuídos. Além disso, a participação e envolvimento da população local se torna essencial para se promover o desenvolvimento do turismo sustentável.

\subsection{Complementação do "Método para construção, estruturação e implementação de projetos em circuitos e roteiros turísticos"}

O processo de formatação de atrativos turísticos sustentáveis aqui apresentado propõe uma abordagem técnica com informações e ferramentas práticas tanto para o micro e pequeno empresário do segmento de atrativos turísticos, quanto para os técnicos gestores de projetos de turismo do SEBRAE-SP.

A complementação metodológica proposta neste trabalho, será aplicada efetivamente nos dois níveis que compõem o referido método, especificamente no nível 1 na fase 4 na etapa de implementação do projeto e no nível 2 na fase 8 na etapa de implementação do projeto. A aplicação da complementação metodológica nestas etapas se justifica uma vez que são aplicadas as ferramentas e produtos necessários para a realização das ações, tendo como referência o foco do projeto e os produtos elaborados para cada segmento de público alvo.

Tal processo se daria a partir do encadeamento lógico de etapas, como um conjunto de medidas tomadas para se atingir um determinado resultado. A formatação de atrativos turísticos se dará em três etapas, denominadas "etapa de interpretação", "etapa de diagnóstico" e "etapa de intervenção", como mostra a figura 2: 
Figura 2- Etapas de formatação de atrativo turístico sustentável

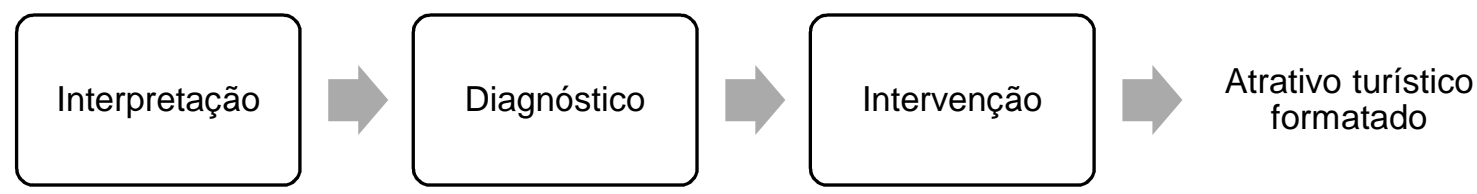

Fonte: Elaborado pelos autores (2014)

Segue, de forma pormenorizada, o descritivo de cada etapa.

Etapa 1 - Interpretação:

A etapa de interpretação prevê a análise prévia das informações e características do atrativo turístico e de sua potencialidade para ser utilizado turisticamente. Essa análise deve ser entendida como o principal aspecto no desenvolvimento de um atrativo turístico sustentável, pois é a partir dessa análise que poderá ser identificada e considerada a possibilidade de formatação e/ou adequação dos atrativos turísticos, bem como a determinação da vocação turística do atrativo. A falta desta vocação turística ou a impossibilidade de formatação e/ou adequação irá interromper todo o processo de formatação e/ou adequação de atrativos turísticos sustentáveis.

As informações existentes nesta etapa são importantes para a determinação da identidade e vocação do atrativo turístico. Estas informações são necessárias para que o proprietário e/ou gestor do atrativo turístico possa analisar os recursos existentes no atrativo e, a partir da identificação destes recursos, ter subsídios para a tomada de decisão sobre o processo de formatação do atrativo turístico.

O quadro 2, apresenta as informações que deverão ser coletadas para se realizar a etapa de interpretação de atrativos turísticos sustentáveis, bem como os resultados esperados: 
Quadro 2 - Informações do formulário de interpretação de atrativos turísticos sustentáveis

\begin{tabular}{|c|c|c|}
\hline Item & Informações & Resultados Esperados \\
\hline $\begin{array}{l}\text { Desenvolvimento } \\
\text { do produto } \\
\text { turístico }\end{array}$ & $\begin{array}{l}\text { Tipo de intervenção que será necessária } \\
\text { no atrativo turístico. Esta intervenção } \\
\text { poderá ser formatação ou adequação. }\end{array}$ & $\begin{array}{l}\text { Estabelecer o tipo de intervenção } \\
\text { (formatação ou adequação) para o } \\
\text { desenvolvimento do atrativo } \\
\text { turístico sustentável }\end{array}$ \\
\hline Vocação turística & $\begin{array}{l}\text { Presença de ocorrências naturais e } \\
\text { ocorrências culturais destacando a } \\
\text { potencialidade de utilização do recurso } \\
\text { de acordo com sua especialidade } \\
\text { (aventura, ecológico, aquático, histórico, } \\
\text { rural, produção artesanal, etc) }\end{array}$ & $\begin{array}{l}\text { Identificação das ocorrências } \\
\text { (naturais ou culturais) para } \\
\text { estabelecer a vocação do atrativo } \\
\text { turístico }\end{array}$ \\
\hline Localização & $\begin{array}{l}\text { Localização do atrativo turístico - área } \\
\text { urbano ou rural }\end{array}$ & $\begin{array}{l}\text { Compreender a localização do } \\
\text { empreendimento para subsidiar o } \\
\text { processo de formatação de atrativo } \\
\text { turístico sustentável }\end{array}$ \\
\hline Tipo de acesso & $\begin{array}{l}\text { Forma de se acessar o atrativo turístico } \\
\text { (terrestre - pavimentado ou não, fluvial, } \\
\text { marítimo ou aéreo) }\end{array}$ & $\begin{array}{l}\text { Compreender os tipos de acesso } \\
\text { para o empreendimento afim de } \\
\text { subsidiar o processo de } \\
\text { formatação de atrativo turístico } \\
\text { sustentável }\end{array}$ \\
\hline $\begin{array}{l}\text { Condições de } \\
\text { receber turistas }\end{array}$ & $\begin{array}{l}\text { Analisar se atualmente a propriedade já } \\
\text { possui condições de receber turistas }\end{array}$ & $\begin{array}{l}\text { Identificar se o empreendimento } \\
\text { possui minimamente estrutura e } \\
\text { condições atuais de receber } \\
\text { turistas para subsidiar o processo } \\
\text { de formatação de atrativo turístico } \\
\text { sustentável }\end{array}$ \\
\hline $\begin{array}{l}\text { Origem dos turistas } \\
\text { que visitam o } \\
\text { município e/ou } \\
\text { região }\end{array}$ & $\begin{array}{l}\text { Localização da origem dos visitantes do } \\
\text { atrativo turístico (local/estadual, } \\
\text { nacional ou internacional) }\end{array}$ & $\begin{array}{l}\text { Identificar o perfil do turista que } \\
\text { visita o município e/ou região que } \\
\text { o atrativo está inserido, para } \\
\text { posterior utilização na etapa de } \\
\text { diagnóstico do processo de } \\
\text { formatação de atrativos turísticos } \\
\text { sustentáveis. }\end{array}$ \\
\hline
\end{tabular}

Fonte: Elaborado pelos autores (2014)

Para esta etapa do processo de formatação de atrativos turísticos sustentáveis, a coleta e análise das informações deverá ser realizada pelo proprietário e/ou gestor da propriedade, uma vez que ele necessitará determinar - na próxima etapa do processo de formatação de atrativos turísticos sustentáveis - quais as intervenções serão necessárias para transformar a propriedade em um atrativo turístico.

O atrativo a ser desenvolvido deve ter um processo de formatação coerente com os recursos existentes na propriedade, evidenciando assim a importância de se realizar uma análise e 
interpretação adequada. Esta análise e interpretação serão primordiais para as ações da próxima etapa, denominada Diagnóstico.

Etapa 2 - Diagnóstico

A etapa de diagnóstico tem por objetivo diagnosticar e identificar quais as necessidades existentes em uma propriedade para que esta possa ser transformada em um atrativo turístico sustentável. Nesta etapa o proprietário e/ou gestor do atrativo turístico deverá ter em mãos, o resultado da análise e interpretação do atrativo, obtido na etapa anterior.

Espera-se que nesta etapa o proprietário e/ou gestor do atrativo turístico possa consolidar as informações existentes no atrativo turístico, conforme a estrutura desenvolvida para a formatação de atrativos turísticos sustentáveis, e a partir disto ter condições de avaliar quais as adequações que se farão necessárias para se formatar o atrativo turístico.

Para se estabelecer um padrão nas informações, foram estabelecidos cinco eixos estratégicos, a partir dos principais aspectos que são necessários em um atrativo turístico. Estes aspectos referem-se à estrutura física, bem como nos processos gerenciais e no aproveitamento dos recursos naturais, partindo-se do pressuposto que os recursos turísticos necessitam de investimentos e melhorias para se transformarem em um atrativo turístico. Estes investimentos e melhorias serão analisados e considerados a partir do resultado desta etapa de diagnóstico, pois a partir do que for identificado no diagnóstico o proprietário e/ou gestor do atrativo turístico poderá mensurar os investimentos necessários para a formatação de atrativo turístico sustentável.

Os cinco eixos estratégicos são:

EIXO 1: Características do produto: compreende aspectos gerais relacionados à sinalização interna e externa, vias de acesso externo, serviços de monitoria, bem como compreensão de fatos históricos, aspectos culturais, características da natureza dentre outros.

EIXO 2: Estrutura Física: compreende aspectos gerais relacionados à infraestrutura para acessos internos, utilização e preservação do atrativo turístico;

EIXO 3: Segurança: compreende aspectos gerais relacionados à segurança e proteção no atrativo turístico para turistas e colaboradores internos.

EIXO 4: Gestão: compreende aspectos gerais relacionados ao gerenciamento do atrativo turístico e também às questões ligadas à sustentabilidade. 
EIXO 5: Divulgação e Comercialização: compreende aspectos gerais relacionados à conquista de clientes/turistas para o atrativo turístico.

$\mathrm{Na}$ definição destes eixos estratégicos, levou-se em consideração aspectos relacionados à sustentabilidade, em especial o consenso do conceito de desenvolvimento sustentável obtido no evento Rio-92, que apontou que este desenvolvimento estava alicerçado, no mínimo, em três dimensões: econômica, ambiental e a social. A partir desse consenso, utilizou-se essas dimensões para se desenvolver estes eixos estratégicos.

O quadro 3 apresenta os eixos estratégicos correlacionados com essas dimensões de sustentabilidade, sendo:

Quadro 3 - Correlação dos eixos estratégicos com dimensões de sustentabilidade

\begin{tabular}{|l|c|l|}
\hline \multicolumn{1}{|c|}{$\begin{array}{c}\text { EIXO } \\
\text { ESTRATÉGICO }\end{array}$} & $\begin{array}{c}\text { DIMENSÃO DE } \\
\text { SUSTENTABILIDADE }\end{array}$ & \multicolumn{1}{c|}{ JUSTIFICATIVA } \\
\hline $\begin{array}{l}\text { Características do } \\
\text { produto }\end{array}$ & Ambiental & $\begin{array}{l}\text { Abordagem de aspectos relacionados à interação } \\
\text { do atrativo turístico ao ambiente que está inserido } \\
\text { e também características da natureza. }\end{array}$ \\
\hline Estrutura Física & Ambiental & $\begin{array}{l}\text { Abordagem de aspectos relacionados à interação } \\
\text { do atrativo turístico ao ambiente que está inserido } \\
\text { e também características da natureza. }\end{array}$ \\
\hline Segurança & Social e Econômica & $\begin{array}{l}\text { Abordagem de questões relacionadas à segurança } \\
\text { dos turistas e dos colaboradores internos. }\end{array}$ \\
\hline Gestão & Ambiental, Social e \\
Econômica & $\begin{array}{l}\text { Abordagem sobre os diferenciais estratégicos do } \\
\text { atrativo turístico, o que engloba a abordagem dos } \\
\text { aspectos de desenvolvimento sustentável } \\
\text { ambiental. }\end{array}$ \\
\hline $\begin{array}{l}\text { Promoção e } \\
\text { Comercialização }\end{array}$ & Econômico & $\begin{array}{l}\text { Abordagem sobre questões de posicionamento } \\
\text { mercadológico. }\end{array}$ \\
\hline
\end{tabular}

Fonte: Elaborado pelos autores (2014)

Os eixos estratégicos são apresentados em blocos, sendo que para cada bloco há itens que compõem cada um desses eixos estratégicos. O proprietário e/ou gestor do atrativo turístico poderá registrar se há ou não a ocorrência destes itens apresentados, além da possibilidade de registrar a não aplicabilidade de algum item - caso seja identificado e interpretado dessa forma. Ao final de cada bloco há ainda a opção do proprietário e/ou gestor do atrativo turístico registrar alguma informação complementar que julgue necessária e que poderá subsidiar a elaboração da próxima etapa, denominada Intervenção.

O quadro 4 demonstra as possibilidades de registros que poderão ser efetuados a partir dos eixos estratégicos com seus itens, demonstrando as ocorrências identificadas: 
Quadro 4 - Formulário simplificado de adequação de atrativos turísticos sustentáveis

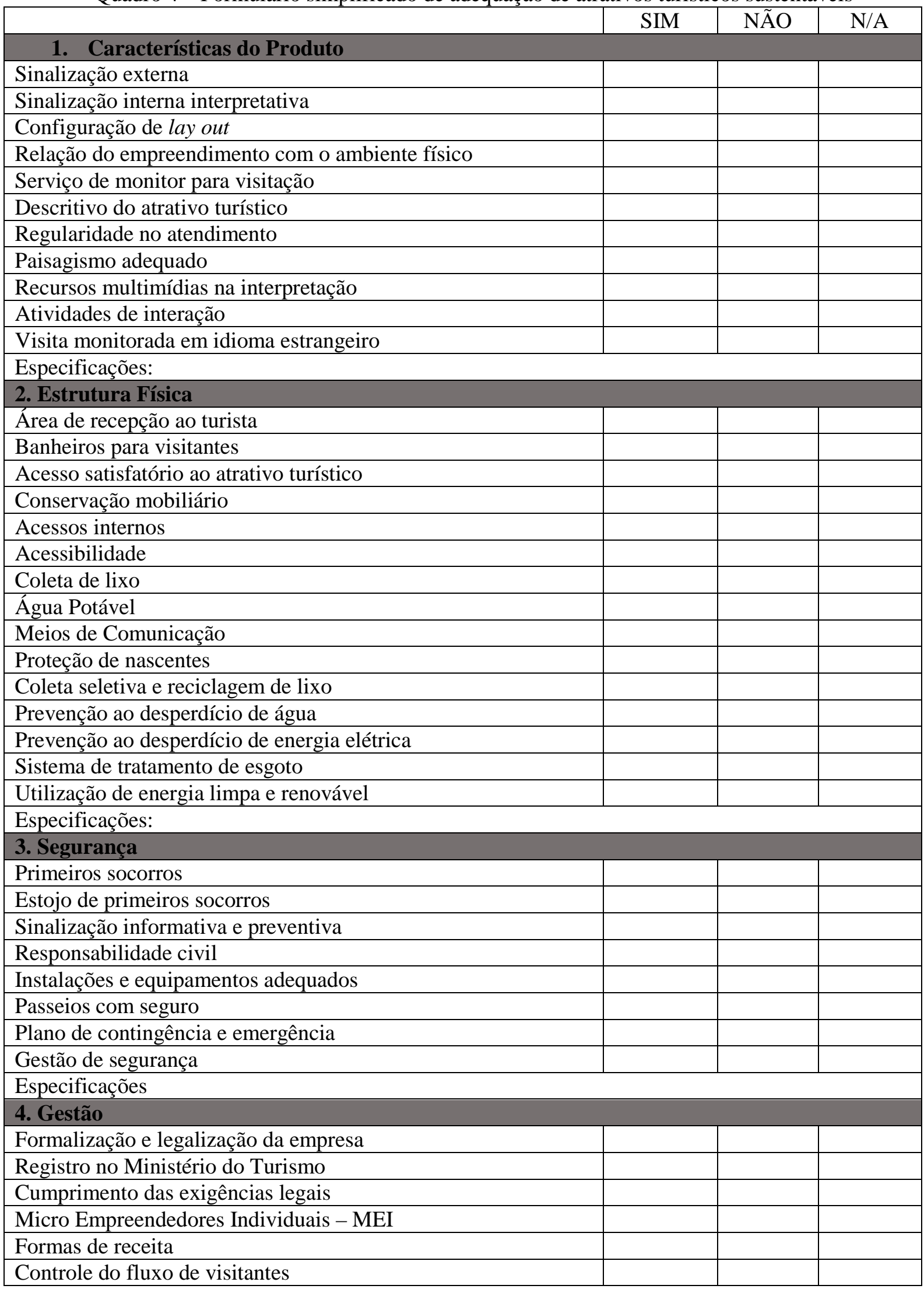




\begin{tabular}{|l|l|l|l|}
\hline Pesquisa de avaliação & & & \\
\hline Capacitação continuada de gestores e funcionários & & & \\
\hline Atuação em rede & & & \\
\hline Regulamento interno & & & \\
\hline Programa de sustentabilidade & & & \\
\hline Especificaç̃̃es: & & & \\
\hline 5. Promoção e Comercialização & & & \\
\hline Material promocional & & & \\
\hline Material de divulgação de atrativos & & & \\
\hline Precificação & & & \\
\hline Site & & & \\
\hline Canais de comercialização & & & \\
\hline Campanhas permanentes & & & \\
\hline Linhas de produtos & & & \\
\hline Cartão de crédito & & & \\
\hline Comércio eletrônico & & & \\
\hline Gestão de clientes & & & \\
\hline Mídias Sociais & & & \\
\hline Parcerias estratégicas & & & \\
\hline Especificaç̃̃es: & & & \\
\hline
\end{tabular}

(N/A significa 'não se aplica')

Fonte: Elaborado pelos autores (2014)

Para facilitar o processo de diagnóstico do atrativo turístico, levou-se em consideração a origem do turista que visita o município e/ou região que o atrativo está inserido. Esta informação é importante, pois de acordo com a origem do turista, o proprietário e/ou gestor do atrativo turístico irá definir quais os itens, de cada eixo estratégico, deverão ser implementados. Para o empresário que está iniciando o desenvolvimento de um atrativo turístico e não possui nenhuma informação sobre a origem de turistas do seu município e/ou região, pode adotar como ponto de partida as adequações para a origem de turistas de abrangência local/estadual, uma vez que estas adequações são compreendidas como as adequações mínimas que qualquer atrativo turístico sustentável deverá possuir.

$\mathrm{O}$ quadro 5 demonstra quais as adequações deverão ser implementadas a partir da identificação da origem do fluxo turístico do atrativo: 
Quadro 5 - Matriz de adequação de atrativos turísticos sustentáveis

\begin{tabular}{|c|c|c|c|}
\hline & $\begin{array}{l}\text { LOCAL/ } \\
\text { ESTADUAL }\end{array}$ & NACIONAL & INTERNACIONAL \\
\hline \multicolumn{4}{|l|}{ Características do Produto } \\
\hline Sinalização externa & $\mathrm{X}$ & $\mathrm{X}$ & $\mathrm{X}$ \\
\hline Sinalização interna interpretativa & & $\mathrm{X}$ & $\mathrm{X}$ \\
\hline Configuração de lay out & $\mathrm{X}$ & $\mathrm{X}$ & $\mathrm{X}$ \\
\hline $\begin{array}{l}\text { Relação do empreendimento com o } \\
\text { ambiente físico }\end{array}$ & $X$ & $X$ & $\mathrm{X}$ \\
\hline Serviço de monitor para visitação & & $\mathrm{X}$ & $\mathrm{X}$ \\
\hline Descritivo do atrativo turístico & & $\mathrm{X}$ & $\mathrm{X}$ \\
\hline Regularidade no atendimento & $\mathrm{X}$ & $\mathrm{X}$ & $\mathrm{X}$ \\
\hline Paisagismo adequado & & $\mathrm{X}$ & $\mathrm{X}$ \\
\hline $\begin{array}{l}\text { Recursos multimídias na } \\
\text { interpretação }\end{array}$ & & $\mathrm{X}$ & $\mathrm{X}$ \\
\hline Atividades de interação & & $\mathrm{X}$ & $\mathrm{X}$ \\
\hline $\begin{array}{l}\text { Visita monitorada em idioma } \\
\text { estrangeiro }\end{array}$ & & & $\mathrm{X}$ \\
\hline \multicolumn{4}{|l|}{ Estrutura Física } \\
\hline Área de recepção ao turista & $\mathrm{X}$ & $\mathrm{X}$ & $\mathrm{X}$ \\
\hline Banheiros para visitantes & $\mathrm{X}$ & $\mathrm{X}$ & $\mathrm{X}$ \\
\hline $\begin{array}{l}\text { Acesso satisfatório ao atrativo } \\
\text { turístico }\end{array}$ & $\mathrm{X}$ & $\mathrm{X}$ & $\mathrm{X}$ \\
\hline Conservação mobiliário & $\mathrm{X}$ & $\mathrm{X}$ & $\mathrm{X}$ \\
\hline Acessos internos & $\mathrm{X}$ & $\mathrm{X}$ & $\mathrm{X}$ \\
\hline Acessibilidade & $\mathrm{X}$ & $\mathrm{X}$ & $\mathrm{X}$ \\
\hline Coleta de lixo & $\mathrm{X}$ & $\mathrm{X}$ & $\mathrm{X}$ \\
\hline Água Potável & $\mathrm{X}$ & $\mathrm{X}$ & $\mathrm{X}$ \\
\hline Meios de Comunicação & $\mathrm{X}$ & $\mathrm{X}$ & $\mathrm{X}$ \\
\hline Proteção de nascentes & $\mathrm{X}$ & $\mathrm{X}$ & $\mathrm{X}$ \\
\hline Coleta seletiva e reciclagem de lixo & $\mathrm{X}$ & $\mathrm{X}$ & $\mathrm{X}$ \\
\hline Prevenção ao desperdício de água & $\mathrm{X}$ & $\mathrm{X}$ & $\mathrm{X}$ \\
\hline $\begin{array}{l}\text { Prevenção ao desperdício de } \\
\text { energia elétrica }\end{array}$ & $\mathrm{X}$ & $\mathrm{X}$ & $\mathrm{X}$ \\
\hline Sistema de tratamento de esgoto & $\mathrm{X}$ & $\mathrm{X}$ & $\mathrm{X}$ \\
\hline $\begin{array}{l}\text { Utilização de energia limpa e } \\
\text { renovável }\end{array}$ & $X$ & $X$ & $X$ \\
\hline \multicolumn{4}{|l|}{ Segurança } \\
\hline Primeiros socorros & $\mathrm{X}$ & $\mathrm{X}$ & $\mathrm{X}$ \\
\hline Estojo primeiros socorros & $\mathrm{X}$ & $\mathrm{X}$ & $\mathrm{X}$ \\
\hline $\begin{array}{l}\text { Sinalização informativa e } \\
\text { preventiva }\end{array}$ & $\mathrm{X}$ & $\mathrm{X}$ & $\mathrm{X}$ \\
\hline Seguro de responsabilidade civil & $\mathrm{X}$ & $\mathrm{X}$ & $\mathrm{X}$ \\
\hline $\begin{array}{l}\text { Instalações e equipamentos } \\
\text { adequados }\end{array}$ & $\mathrm{X}$ & $\mathrm{X}$ & $\mathrm{X}$ \\
\hline Passeios e atividades com seguro & & $\mathrm{X}$ & $\mathrm{X}$ \\
\hline $\begin{array}{l}\text { Plano de contingencia e } \\
\text { emergência }\end{array}$ & & $\mathrm{X}$ & $\mathrm{X}$ \\
\hline Gestão de segurança & $\mathrm{X}$ & $\mathrm{X}$ & $\mathrm{X}$ \\
\hline
\end{tabular}




\begin{tabular}{|c|c|c|c|}
\hline \multicolumn{4}{|l|}{ Gestão } \\
\hline $\begin{array}{l}\text { Formalização e legalização da } \\
\text { empresa }\end{array}$ & $X$ & $X$ & $\mathrm{X}$ \\
\hline Registro no Ministério do Turismo & $\mathrm{X}$ & $\mathrm{X}$ & $\mathrm{X}$ \\
\hline Cumprimento das exigências legais & $\mathrm{X}$ & $\mathrm{X}$ & $X$ \\
\hline $\begin{array}{l}\text { Micro Empreendedores Individuais } \\
\text { - MEI }\end{array}$ & & $X$ & $\mathrm{X}$ \\
\hline Formas de receita & $\mathrm{X}$ & $X$ & $\mathrm{X}$ \\
\hline Controle do fluxo de visitantes & & $\mathrm{X}$ & $\mathrm{X}$ \\
\hline Pesquisa de avaliação & & $\mathrm{X}$ & $\mathrm{X}$ \\
\hline $\begin{array}{l}\text { Capacitação continuada de gestores } \\
\text { e funcionários }\end{array}$ & & $\mathrm{X}$ & $\mathrm{X}$ \\
\hline Atuação em rede & & $\mathrm{X}$ & $\mathrm{X}$ \\
\hline Regulamento interno & $\mathrm{X}$ & $\mathrm{X}$ & $\mathrm{X}$ \\
\hline Programa de sustentabilidade & $\mathrm{X}$ & $\mathrm{X}$ & $\mathrm{X}$ \\
\hline \multicolumn{4}{|l|}{ Promoção e Comercialização } \\
\hline Material promocional & $X$ & $X$ & $\mathrm{X}$ \\
\hline Material de divulgação de atrativos & $\mathrm{X}$ & $\mathrm{X}$ & $\mathrm{X}$ \\
\hline Precificação & $\mathrm{X}$ & $\mathrm{X}$ & $\mathrm{X}$ \\
\hline Site & & $\mathrm{X}$ & $\mathrm{X}$ \\
\hline Canais de comercialização & $\mathrm{X}$ & $\mathrm{X}$ & $\mathrm{X}$ \\
\hline Campanhas permanentes & & $\mathrm{X}$ & $\mathrm{X}$ \\
\hline Linhas de produtos & & $\mathrm{X}$ & $\mathrm{X}$ \\
\hline Cartão de crédito & & $\mathrm{X}$ & $\mathrm{X}$ \\
\hline Comércio eletrônico & & $\mathrm{X}$ & $\mathrm{X}$ \\
\hline Gestão de clientes & & $X$ & $X$ \\
\hline Mídias Sociais & $\mathrm{X}$ & $\mathrm{X}$ & $X$ \\
\hline Parcerias estratégicas & $\mathrm{X}$ & $\mathrm{X}$ & $\mathrm{X}$ \\
\hline
\end{tabular}

Fonte: Elaborado pelos autores (2014)

Para se realizar a etapa de diagnóstico, tendo como referência a matriz de adequação apresentada, é possível avaliar quais os itens já existem nos atrativos turísticos e quais os itens deverão ser implementados, para que o atrativo turístico possa ser visitado e usufruído pelos turistas, ao mesmo tempo em que gere lucro aos seus proprietários. Realizada esta etapa devese prosseguir para a última etapa do processo de formatação do atrativo turístico sustentável. Etapa 3 - Interpretação

Esta última etapa do processo de formatação de atrativos turísticos sustentáveis consiste na elaboração e avaliação de um plano de ação para que haja um planejamento e acompanhamento na implementação dos componentes de formatação. Nesta etapa, que deverá ser elaborada pelo proprietário e/ou gestor do atrativo turístico, deve-se apresentar todas as adequações identificadas no campo "NÃO" no formulário de diagnóstico do atrativo turístico sustentável, ou seja, os itens que foram identificados como precários ou inexistentes deverão 
compor este plano de ação visando atender a matriz de adequação apresentada no item anterior.

Neste formulário, o proprietário e/ou gestor do atrativo turístico irá definir um cronograma para a implementação dos itens de cada eixo estratégico, indicando neste documento as adequações necessárias identificadas.

Após a elaboração do plano de ação, o proprietário e/ou gestor do atrativo turístico deverá fazer a avaliação periódica da implementação das ações propostas de acordo com os prazos estabelecidos. Esta avaliação tem por objetivo identificar se as intervenções propostas foram realizadas dentro do prazo estipulado e se estão em conformidade com as observações geradas na elaboração do plano de ação.

A periodicidade desta avaliação deverá ser definida pelo proprietário e/ou gestor do atrativo turístico, de acordo com sua disponibilidade de tempo para realizar esta ação. Para caracterizar a conclusão da etapa de intervenção, o proprietário e/ou gestor do atrativo turístico deverá realizar um novo diagnóstico com o objetivo de registrar a efetiva implementação das adequações identificadas e listadas no plano de ação.

Ao se concluir a última etapa, que inclui intervenção, implementação e verificação, podemos afirmar que o atrativo turístico passou pelo processo de formatação de atrativos turísticos sustentáveis, aprimorando desta forma a oferta turística diferencial do destino no qual está inserido.

Para que esta complementação se torne parte do portfólio do SEBRAE-SP, deverá passar por um processo de avaliação e validação, seguindo os procedimentos metodológicos adotados pelo SEBRAE-SP para o desenvolvimento de novos produtos. Estes procedimentos metodológicos consistem na aplicação de três etapas complementares entre si que consistem em: 1.) análise técnica do material desenvolvido, analisando não só o conteúdo, mas também a sua identidade visual de acordo com os padrões estabelecidos pela instituição; 2) identificação e seleção de um possível território com a definição da(s) empresa(s) que possivelmente receberão a aplicação do produto desta pesquisa. Ao se definir o território bem como o público alvo, faz-se necessário o contato com o Escritório Regional responsável, para o acompanhamento da aplicação deste piloto, que deverá ser realizada pela equipe responsável pelo seu desenvolvimento. Nesta etapa realiza-se um acompanhamento das empresas participantes desse piloto para a avaliação do processo desde a sua etapa inicial até a 
mensuração dos resultados esperados. Ao longo desta etapa os procedimentos constantes nesta complementação metodológica são analisados e as correções que por ventura se fizerem necessárias são realizadas; 3 ) a última etapa consiste na efetivação da entrega do produto final como um produto do portfólio do SEBRAE-SP, onde posteriormente, serão realizados os treinamentos e capacitações necessárias aos funcionários que estiverem aptos a operacionalizar tal produto.

\section{Conclusão}

O planejamento e formatação de atrativos turísticos sustentáveis é imperativo no desenvolvimento de um destino turístico, uma vez que esse elemento compõe a oferta turística diferencial de uma localidade e está diretamente ligado com a sustentabilidade a medida que a sua estrutura aborda questões ambientais, econômicas e sociais.

A gestão dos atrativos turísticos deve ser executada de forma profissional, para atender às necessidades dos turistas atuais, garantindo infraestrutura necessária, segurança, qualidade de serviços e demais elementos importantes para a recepção dos visitantes.

Assim, o atrativo turístico deve ser planejado, considerando todos os aspectos socioambientais e do seu entorno e, simultaneamente as questões mercadológicas que garantam a viabilidade econômica do empreendimento.

Diante disto, pode-se afirmar que o processo de formatação apresentado neste trabalho é pioneiro no ponto de vista de atrativo turístico enquanto negócio, e pode ser considerada como um documento de análise e orientação para gestores de destinos turísticos, que visam o seu desenvolvimento e, principalmente, para gestores de atrativos turísticos, que devem buscar a excelência do seu negócio, considerando todos os aspectos inerentes, tais como: caracterização, estrutura física, segurança, gestão, promoção e comercialização.

A partir deste processo de formatação de atrativos turísticos sustentáveis, informações técnicas poderão ser identificadas, coletadas, analisadas e aplicadas de maneira prática possibilitando assim aprimorar produtos e serviços dos atrativos turísticos, com foco na melhoria de sua competitividade empresarial. Desta forma, este processo de formatação de 
atrativos turísticos sustentáveis poderá apoiar os proprietários e/ou gestores de atrativos turísticos na tomada de decisão para a definição de suas estratégias.

Conforme apresentado anteriormente, este trabalho teve como objetivo geral desenvolver um processo de formatação de atrativos turísticos sustentáveis, que poderá ser incorporado a metodologia de turismo do SEBRAE-SP. Para tanto, procurou-se realizar uma revisão bibliográfica sobre temas relacionados ao planejamento estratégico, e desenvolvimento sustentável do turismo e oferta turística diferencial.

Durante a realização da pesquisa observou-se que a literatura existente sobre atrativos turísticos não é tão ampla se comparada a outros temas de turismo de uma forma geral. Houve por parte do autor, dificuldade em encontrar modelos de planejamento turístico que tratassem de forma mais clara a questão da formatação de atrativos turísticos. Estes aspectos constituem-se como desafios desse trabalho, mas também reforçam o aspecto inovador dessa iniciativa. Retomando os objetivos apresentados no início deste trabalho, acredita-se que os mesmos foram alcançados de forma satisfatória. Para a incorporação desta complementação metodológica no portfólio do SEBRAE-SP faz-se necessária a sua aplicação prática para comprovação de sua eficácia e obtenção dos resultados propostos.

Para tanto, a unidade responsável pelo desenvolvimento de conteúdos técnicos e a unidade de projetos deverão conjuntamente analisar tal proposição a fim de incorporá-lo como produto oficial do SEBRAE-SP. Após essa análise, deve-se adotar um território como piloto e aplicar os procedimentos de avaliação de produtos do SEBRAE-SP.

Espera-se que o resultado deste estudo contribua de forma prática para o aprimoramento da estruturação de atrativos turísticos, e que a partir deste aperfeiçoamento possa se elevar a competitividade da oferta turística diferencial e consequentemente dos destinos turísticos. $\mathrm{E}$ que o resultado do estudo aqui apresentado possa subsidiar de alguma forma outros estudos e discussões sobre a formatação de atrativos turísticos sustentáveis.

\section{Referências}

ANSARAH, M. G. dos R. (Org.). Turismo: como aprender, como ensinar. São Paulo: Senac, 2001.

BADARÓ, R. A. de L. Direito internacional do turismo: o papel das organizações internacionais no turismo. São Paulo: Senac, 2008. 
BENI, M. C. Análise estrutural do turismo. 13.ed. São Paulo: Senac. 2008.

BRAGA, D. C. Planejamento turístico: teoria e prática. 2a reimp. Rio de Janeiro: Campus, 2007.

BRASIL. Ministério do Turismo. Coordenação Geral de Regionalização. Programa de Regionalização do Turismo - Roteiros do Brasil: Módulo Operacional 7. Roteirização Turística. Brasília: Ministério do Turismo, 2007. 51 p.

CÁRDENAS TABARES, F. Proyectos turísticos: localización e inversión. México: Trillas, 1994.

COOPER, C.; FLETCHER, J.; STEPHEN, W.; GILBERT, D.; SHEPHERD, R. Turismo: princípios e prática. 2.ed. São Paulo: Bookman, 2001.

CORIOLANO, L. M. N. T. O turismo nos discursos, nas políticas e no combate à pobreza. São Paulo: Annablume, 2006.

DENCKER, A. F. M. Pesquisa em turismo: planejamento, métodos e técnicas. 9.ed. São Paulo: Futura, 2007.

GLOBE'90. Tourism stream and action committee. An action strategy for susteinable tourism development. Vancouver: BC, 1990.

IGNARRA, L. R. Fundamentos do turismo. 2. ed. São Paulo: Thomson, 2003.

LOHMANN, G.; PANOSSO NETTO, A. Teoria do turismo: conceitos, modelos e sistemas. 2. ed. São Paulo: Aleph, 2012.

MINISTÉRIO DO TURISMO. Estatísticas básicas de turismo. Disponível em: Acesso em: 10 de abril de 2014.

MINISTÉRIO DO TURISMO. Inventário da oferta turística - Brasília: Ministério do Turismo, 2011. $38 \mathrm{p}$.

MINISTÉRIO DO TURISMO. Missão. Disponível em: Acesso em: 19 de março de 2014.

MOLINA, S., RODRÍGUEZ, S. A. Planejamento integral do turismo: um enfoque para América Latina, Bauru: EDUSC, 2001.

NACIONES UNIDAS. Cuenta satélite de turismo: recomendaciones sobre el marco conceptual. Madrid: Naciones Unidas, 2008.

PETROCCHI, M. Turismo: planejamento e gestão. 3.ed. São Paulo: Futura, 2001.

RUSCHMANN, D.V. de M. Turismo e planejamento sustentável: a proteção do meio ambiente. Campinas: Papirus, 1997.

SECRETARIA DE TURISMO DO ESTADO DE SÃO PAULO, 2013. Disponível em: <http://www.turismo.sp.gov.br/>.Acesso em 31 de maio de 2014.

TRIGO, L. G. G. A sociedade pós-industrial e o profissional em turismo. 7. ed. Campinas, SP: Papirus, 2003. $251 \mathrm{p}$. . Termo de referência para atuação no turismo receptivo. São Paulo: SEBRAE-SP, 2011. 61 p.

\section{Recebido em: 08/12/2014 (1 ${ }^{\mathrm{a}}$ versão) $23 / 09 / 2015$ ( $2^{\mathrm{a}}$ versão) \\ Aprovado em: 06/10/2015}

